\title{
Ambipolar SnOx Thin-Film Transistors Achieved at High Sputtering Power
}

DOI:

$10.1063 / 1.5022875$

\section{Document Version}

Accepted author manuscript

Link to publication record in Manchester Research Explorer

\section{Citation for published version (APA):}

Yunpeng Li, Jia Yang, Qu, Y., Zhang, J., Zhou, L., Yang, Z., Lin, Z., Qingpu Wang, Song, A., \& Qian Xin (2018). Ambipolar SnOx Thin-Film Transistors Achieved at High Sputtering Power. Applied Physics Letters, 112, [182102]. https://doi.org/10.1063/1.5022875

\section{Published in:}

Applied Physics Letters

\section{Citing this paper}

Please note that where the full-text provided on Manchester Research Explorer is the Author Accepted Manuscript or Proof version this may differ from the final Published version. If citing, it is advised that you check and use the publisher's definitive version.

\section{General rights}

Copyright and moral rights for the publications made accessible in the Research Explorer are retained by the authors and/or other copyright owners and it is a condition of accessing publications that users recognise and abide by the legal requirements associated with these rights.

\section{Takedown policy}

If you believe that this document breaches copyright please refer to the University of Manchester's Takedown Procedures [http://man.ac.uk/04Y6Bo] or contact uml.scholarlycommunications@manchester.ac.uk providing relevant details, so we can investigate your claim.

\section{OPEN ACCESS}




\title{
Ambipolar $\mathrm{SnO}_{\mathrm{x}}$ Thin-Film Transistors Achieved at High Sputtering Power
}

\author{
Yunpeng Li ${ }^{1}$, Jia Yang ${ }^{1}$, Yunxiu Qu ${ }^{1}$, Jiawei Zhang ${ }^{2}$, Li Zhou ${ }^{1}$, Zaixing Yang ${ }^{1}$, Zhaojun Lin ${ }^{1}$, \\ Qingpu Wang ${ }^{1}$, Aimin Song ${ }^{1,2, a)}$, and Qian Xin ${ }^{1, a)}$ \\ ${ }^{1}$ Center of Nanoelectronics, State Key Laboratory of Crystal Materials, and School of Microelectronics, \\ Shandong University, Jinan 250100, China \\ ${ }^{2}$ School of Electrical and Electronic Engineering, University of Manchester, Manchester M13 9PL, United \\ Kingdom
}

$\mathrm{SnO}$ is the only oxide semiconductor to date that has exhibited ambipolar behavior in thin-film transistors (TFTs). In this work, ambipolar behavior was observed in $\mathrm{SnO}_{\mathrm{x}}$ TFTs fabricated at a high sputtering power of $200 \mathrm{~W}$ and post-annealed at $150-250{ }^{\circ} \mathrm{C}$ in ambient air. X-raydiffraction patterns show polycrystallisation of $\mathrm{SnO}$ and $\mathrm{Sn}$ in the annealed $\mathrm{SnO}_{\mathrm{x}}$ films. Scanning-electron-microscopy images revealed that microgrooves occurred after the films were annealed. Clusters subsequently segregated along the microgrooves, and our experiments suggested that they are most likely Sn clusters. Atomic-force-microscopy images indicated an abrupt increase in film roughness due to the cluster segregations. An important implication of this work is that excess $\mathrm{Sn}$ in the film, which has been generally thought to be detrimental to the film quality, may promote the ambipolar conduction when it is segregated from the film to enhance the stoichiometric balance.

Oxide semiconductors are highly attractive especially for the new generation flexible and wearable electronics due to their low cost, low deposition temperatures, high carrier mobilities $\left(1 \sim 100 \mathrm{~cm}^{2} / \mathrm{Vs}\right)$, good transparency in the visible-light region, and ease of large-area manufacturing. ${ }^{1-4}$ To date, n-type oxides, such as $\mathrm{ZnO}$ and $\mathrm{InGaZnO}$, are highly developed and even commercialized. On the contrary, the development of their p-type counterparts is far behind, and ambipolar oxides that can exhibit both $\mathrm{n}$ - and p-type conduction are even rarer. ${ }^{5-9}$ To fabricate all-oxide-based complementary-metal-oxide-semiconductor (CMOS) -like circuits, it is essential to develop high-performance p-type or ambipolar oxide semiconductors. In particular, ambipolar semiconductors can significantly simplify the fabrication process of

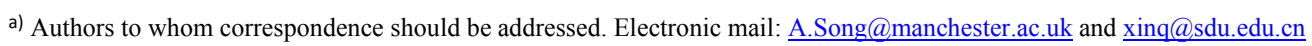


CMOS circuits and allow more compact CMOS architectures. ${ }^{9}$ Hence, extraordinary efforts have been made to develop ambipolar semiconductors and related thin-film-transistors (TFTs). Up to now, nanocrystalline silicon, organic semiconductors, and carbon nanotubes have been found capable of operating in ambipolar mode, due to either a small bandgap or low density of subgap states. ${ }^{8-10}$ Recently, tin monoxide $(\mathrm{SnO})$ has been found capable of operating in ambipolar mode, and this is the only oxide semiconductor capable of conducting both electrons and holes effectively in a TFT. ${ }^{11,12}$ Voltage gains of CMOS-like inverters based on such ambipolar SnO TFTs have been shown to be higher than $100 .^{6}$

Ambipolar behavior is generally difficult to achieve in most oxide TFTs because of their typically large fundamental bandgaps and a high density of subgap states. ${ }^{13-15} \mathrm{SnO}$ is regarded as the most promising p-type oxide among the limited number of p-type oxides discovered so far. ${ }^{12}$ The ambipolar behavior of $\mathrm{SnO}$ has been thought to be due to its low electron effective mass $\left(\sim 0.4 \mathrm{~m}_{0}\right)$, low hole effective mass $\left(\sim 0.6 \mathrm{~m}_{0}\right)$, and small fundamental bandgap $(\sim 0.7$ eV). ${ }^{11,16,17}$ However, the density of subgap states in some p-type SnO TFTs extracted by temperature-dependent field-effect results can be higher than $10^{19} \mathrm{eV}^{-1} \mathrm{~cm}^{-3},{ }^{15,18}$ which supresses the ambipolar behavior. In 2011, Nomura et al. fabricated the first SnO-based ambipolar TFT. ${ }^{11}$ Subsequently, Cao et al. fabricated ambipolar SnO TFT with balanced electron and hole mobilities. ${ }^{5,6}$ In 2016, Chen et al. demonstrated controllability of ambipolar conduction in $\mathrm{SnO}_{\mathrm{x}}$ TFTs by oxygen plasma treatment. ${ }^{19}$ In 2017 , Kim et al. observed clear ambipolar operation in TFTs based on atomic-layer-deposited $\mathrm{SnO}$ films as the active layer. ${ }^{20}$ Despite these processes, studies on how the ambipolar conduction and associated microstructures change in $\mathrm{SnO}$ film under thermal treatment are still limited.

In this work, ambipolar $\mathrm{SnO}_{\mathrm{x}}$ channel layers were achieved by using a high sputtering power of $200 \mathrm{~W}$ and post-annealing in ambient air without passivation. The ambipolar behavior appeared when microgrooves occurred and nanoclusters segregated along the microgrooves in the $\mathrm{SnO}_{\mathrm{x}}$ film. Our study indicates that the appearance of ambipolar behavior is a result of both a reduction of density of subgap states by $\mathrm{Sn}$ interstitials $\left(\mathrm{Sn}_{\mathrm{i}}\right)$ and suppression of interfacial trap states because of the segregation of Sn clusters.

The schematic diagram of our $\mathrm{SnO}_{\mathrm{x}}$ TFTs is shown in Fig. 1(a). Heavily doped p-type silicon wafers were used as both substrates and gate electrodes. 300-nm-thick thermally grown 
$\mathrm{SiO}_{2}$ was employed as the gate dielectrics. $\mathrm{SnO}_{\mathrm{x}}$ active layers were deposited onto the $\mathrm{SiO}_{2}$ surfaces using reactive radio-frequency magnetron sputtering method with a deposition power of $200 \mathrm{~W}$ from a 3 inches $\mathrm{Sn}$ target (99.99\% purity). The $\mathrm{Ar} / \mathrm{O}_{2}$ mixture atmosphere was fixed at a ratio of $23 / 3(\mathrm{sccm} / \mathrm{sccm})$. The working pressure during the sputtering process was $\sim 4.8$ mTorr. The substrate temperature was kept at $100{ }^{\circ} \mathrm{C}$. The thickness of the $\mathrm{SnO}_{\mathrm{x}}$ layers was $27 \mathrm{~nm}$. 50-nm-thick Pd source and drain electrodes were deposited by electron-beam evaporation, and the length and width of the active channel were 60 and $2000 \mu \mathrm{m}$, respectively. Finally, the devices were annealed at $150,175,200,225$, and $250^{\circ} \mathrm{C}$ for 1 hour in ambient air step by step.

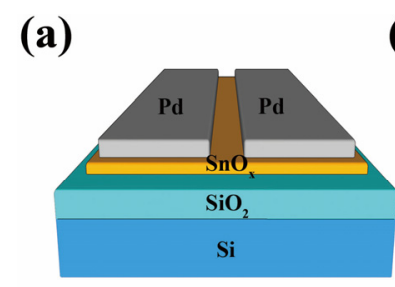

(c)
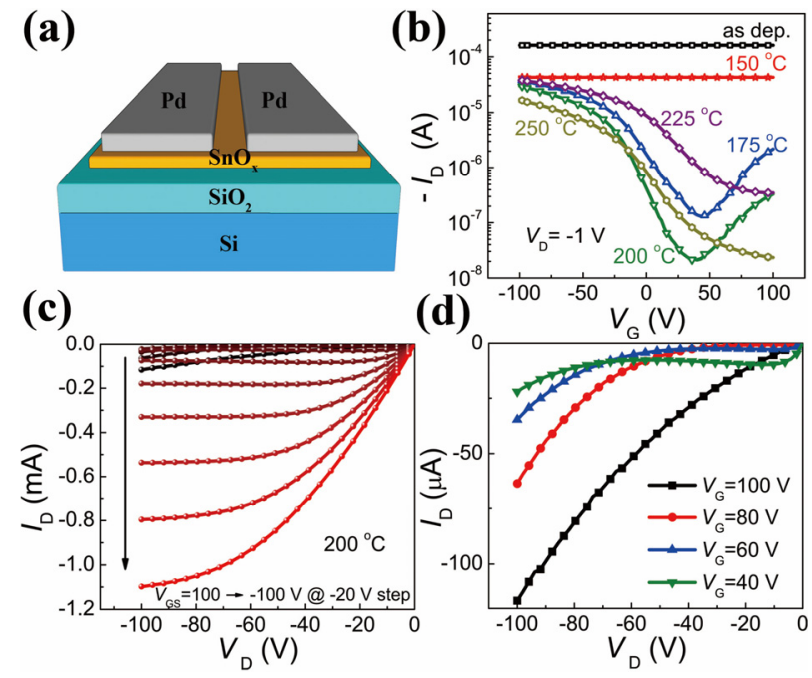

FIG. 1. (a) Schematic diagram of $\mathrm{SnO}_{\mathrm{x}} \mathrm{TFT}$, (b) transfer curves of the as-deposited and annealed (at 150, 175, 200, 225, and $250{ }^{\circ} \mathrm{C}$ ) $\mathrm{SnO}_{\mathrm{x}} \mathrm{TFTs}$, (c) output curves of the TFT postannealed at $200{ }^{\circ} \mathrm{C}$, (d) a zoomed view of figure (c) when $V_{\mathrm{G}}=40-100 \mathrm{~V}$.

Figure 1(b) shows the transfer curves of the TFT annealed at different temperatures. The channel layer of the as-deposited TFT was too conductive to be tuned by gate voltages $V_{\mathrm{G}}$. The source-drain current, $I_{\mathrm{D}}$, decreased by $\sim 4$ times after the TFT was annealed at $150{ }^{\circ} \mathrm{C}$ in air due to oxidation of excess metallic Sn, but still could not be tuned by gate voltage. After the TFT was annealed at 175 and $200^{\circ} \mathrm{C}$, ambipolar behavior was observed. The TFT showed p-type characteristics at negative gate biases and n-type conduction at high positive gate biases ( $>$ $40 \mathrm{~V})$. The on/off ratio reached 288 and 1350 for post-annealing temperatures of 175 and $200{ }^{\circ} \mathrm{C}$, respectively. As shown in Figs. 1(c) and 1(d), the TFT exhibited pronounced p-type 
performance at $V_{\mathrm{G}}$ from +20 to $-100 \mathrm{~V}$, and n-type transport was observed at positive $V_{\mathrm{G}}$ from +40 to $+100 \mathrm{~V}$. Such ambipolar behavior disappeared with the disappearance of the n-type conduction when the TFT was further annealed at 225 and $250{ }^{\circ} \mathrm{C}$.

Electrical parameters (on/off ratio $I_{\mathrm{on}} / I_{\mathrm{off}}$, electron mobility $\mu_{\mathrm{e}}$, hole mobility $\mu_{\mathrm{h}}$, subthreshold voltage swing $S S$, and density of subgap trap states $D_{\mathrm{t}}$ ) of TFTs annealed at various temperatures were summarized in Table I. The field-effect mobility, $\mu$, was extracted from the linear region of the transfer curve by using ${ }^{12}$

$$
I_{\mathrm{D}}=\frac{W}{L} C_{\mathrm{ox}} \mu\left(V_{\mathrm{G}}-V_{\mathrm{th}}\right) V_{\mathrm{D}}
$$

where $W$ and $L$ are the channel width and length, respectively; $C_{\mathrm{ox}}$ is the capacitance per unit area of the dielectric; $V_{\text {th }}$ is the threshold voltage; and $V_{\mathrm{D}}$ is the drain voltage. As shown in Table I, the n-type $\mathrm{SnO}_{\mathrm{x}}$ TFT showed an $\mu_{\mathrm{e}}$ of 0.16 and $0.02 \mathrm{~cm}^{2} /(\mathrm{V} \cdot \mathrm{s})$ with annealing temperatures of 175 and $200{ }^{\circ} \mathrm{C}$, respectively. For the p-type $\mathrm{SnO}_{\mathrm{x}} \mathrm{TFT}$, the $\mu_{\mathrm{h}}$ was $0.97,0.92$, 0.74 , and $0.52 \mathrm{~cm}^{2} /(\mathrm{V} \cdot \mathrm{s})$ with annealing temperatures of $175,200,225$, and $250{ }^{\circ} \mathrm{C}$, respectively.

The $S S$ of the TFT is given by ${ }^{13}$

$$
S S=\left[\frac{\partial\left(\lg I_{\mathrm{D}}\right)}{\partial\left(V_{\mathrm{G}}\right)}\right]^{-1}=\ln (10) \frac{k T}{q}\left(1+\frac{q^{2} D_{\mathrm{t}}}{C_{\mathrm{ox}}}\right),
$$

where $k$ is the Boltzmann constant; $T$ is the temperature; and $q$ is the electron charge. For the p-type $\mathrm{SnO}_{\mathrm{x}} \mathrm{TFT}, \mathrm{SS}$ was $28.36,18.29,38.94$, and $29.61 \mathrm{~V} / \mathrm{dec}$ with annealing temperatures of $175,200,225$, and $250^{\circ} \mathrm{C}$, respectively. $D_{\mathrm{t}}$ extracted from the transfer curves was $3.42 \times 10^{13}$, $2.20 \times 10^{13}, 4.70 \times 10^{13}$, and $3.57 \times 10^{13} \mathrm{~cm}^{-2} \mathrm{eV}^{-1}$ with annealing temperatures of 175,200 , 225 , and $250^{\circ} \mathrm{C}$, respectively.

TABLE I. Electrical parameters of SnO TFTs annealed at 175, 200, 225, and $250^{\circ} \mathrm{C}$.

\begin{tabular}{cccccc}
\hline \hline $\begin{array}{c}\mathrm{T} \\
\left({ }^{\circ} \mathrm{C}\right)\end{array}$ & $I_{\mathrm{on} / I_{\mathrm{off}}}$ & $\begin{array}{c}\mu_{\mathrm{e}} \\
\left(\mathrm{cm}^{2} \mathrm{~V}^{-1} \mathrm{~s}^{-1}\right)\end{array}$ & $\begin{array}{c}\mu_{\mathrm{h}} \\
\left(\mathrm{cm}^{2} \mathrm{~V}^{-1} \mathrm{~s}^{-1}\right)\end{array}$ & $\begin{array}{c}S S \\
(\mathrm{~V} / \mathrm{dec})\end{array}$ & $\begin{array}{c}D_{\mathrm{t}} \\
\left(\mathrm{cm}^{-2} \mathrm{eV}^{-1}\right)\end{array}$ \\
\hline 175 & 288 & 0.16 & 0.97 & 28.36 & $3.42 \times 10^{13}$ \\
200 & 1350 & 0.02 & 0.92 & 18.29 & $2.20 \times 10^{13}$ \\
225 & 108 & - & 0.74 & 38.94 & $4.70 \times 10^{13}$ \\
250 & 728 & - & 0.52 & 29.61 & $3.57 \times 10^{13}$ \\
\hline \hline
\end{tabular}




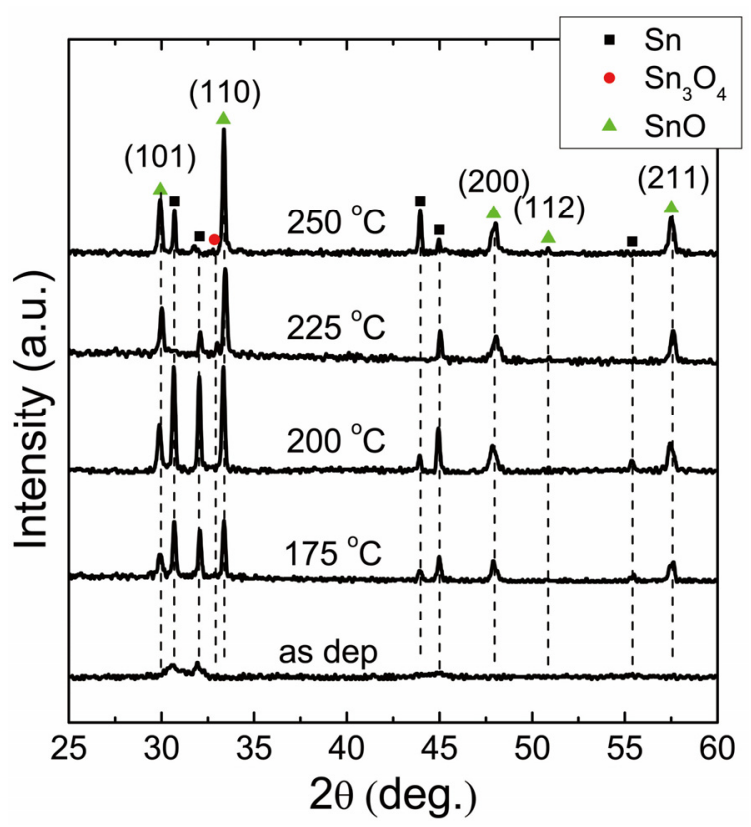

FIG. 2. XRD patterns of one- $\mu \mathrm{m}$-thick as-deposited and annealed (at $175,200,225$, and $250{ }^{\circ} \mathrm{C}$ ) $\mathrm{SnO}_{\mathrm{x}}$ films which are sputtered at $200 \mathrm{~W}$.

Figure 2 presents $\mathrm{XRD}$ patterns of the as-deposited and annealed one- $\mu \mathrm{m}$-thick $\mathrm{SnO}_{\mathrm{x}}$ films. It indicates that there is crystalized $\mathrm{Sn}$ but no crystalized $\mathrm{SnO}$ in the as-deposited film. Peaks of (101), (110), (200), (112), and (211) directions of $\alpha-\mathrm{SnO}$ ( $\alpha$-PbO structure) were detected after the films were annealed. Peaks of $\mathrm{Sn}$ were also detected in the annealed films. $\mathrm{Sn}_{3} \mathrm{O}_{4}$ which is an intermediate oxidation state and can be easily further oxidized to $\mathrm{SnO}_{2}$ by annealing ${ }^{21}$ was detected after the film was annealed at $225^{\circ} \mathrm{C}$. The disappearance of such $\mathrm{Sn}_{3} \mathrm{O}_{4}$ peak after the film was annealed at $250^{\circ} \mathrm{C}$ indicates the formation of $\mathrm{SnO}_{2} . \mathrm{SnO}_{2}$ is not expected to be shown in the XRD spectra because it is expected to be amorphous at the annealing temperatures in this work. ${ }^{22,23}$

Figure 3 shows the surface morphologies of the 27-nm-thick $\mathrm{SnO}_{\mathrm{x}}$ thin films annealed at various temperatures. The as-deposited film was relatively homogeneous and smooth as shown in Fig. 3(a). For the film annealed at $150{ }^{\circ} \mathrm{C}$, feather-like and bright regions (marked by white circle in Fig. 3(b)) were observed and some tiny microgrooves (black region) appeared simultaneously possibly due to formation of polycrystalline of $\mathrm{SnO}$. As the annealing temperature went higher, such feather-like, bright regions and black microgrooves became more obvious (Fig. 3(c)), and needle-like grains started to grow along the microgrooves when 
the film was annealed at temperatures above $162{ }^{\circ} \mathrm{C}$. XRD patterns in Fig. 2 show the crystallization of $\mathrm{SnO}$ and metallic $\mathrm{Sn}$ in the annealed films. The dominated and continuous composition in films annealed at and above $175^{\circ} \mathrm{C}$ should be $\mathrm{SnO}$ due to the observed ambipolar and p-type conduction of TFTs (Fig. 1(b)).
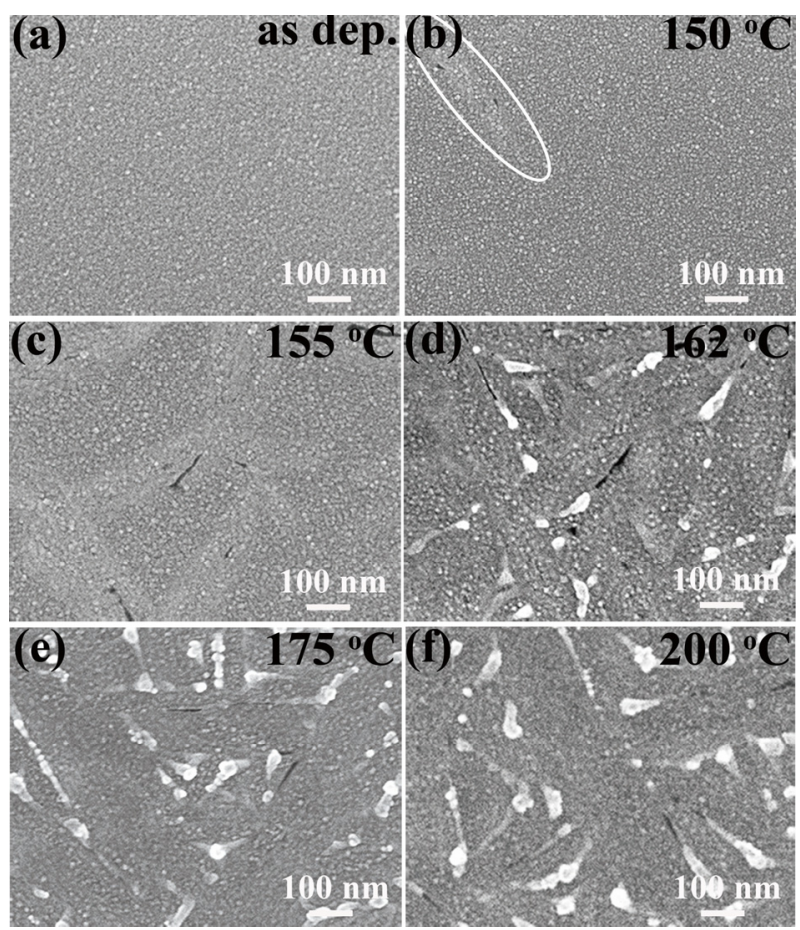

FIG. 3. SEM images of (a) as-deposited $\mathrm{SnO}_{\mathrm{x}}$ film, and $\mathrm{SnO}_{\mathrm{x}}$ films annealed at (b) 150, (c) 155, (d) 162 , (e) 175 , and (f) $200{ }^{\circ} \mathrm{C}$.

Atomic-force-microscopy (AFM) images were taken to study the surface roughness of the films annealed at different temperatures. Figures 4(a) and 4(b) show AFM images of the asdeposited film and film annealed at $200{ }^{\circ} \mathrm{C}$, respectively. Figure 4(c) shows how the root-meansquare (RMS) roughness changes with the annealing temperature. The RMS roughness of the film shows a sharp increase from 0.60 to $3.73 \mathrm{~nm}$ when the film was annealed from 150 to $175^{\circ} \mathrm{C}$. The drastic change of roughness correlates with the significantly improved transistor on/off ratio at similar annealing temperatures as in Fig. 1(b). 

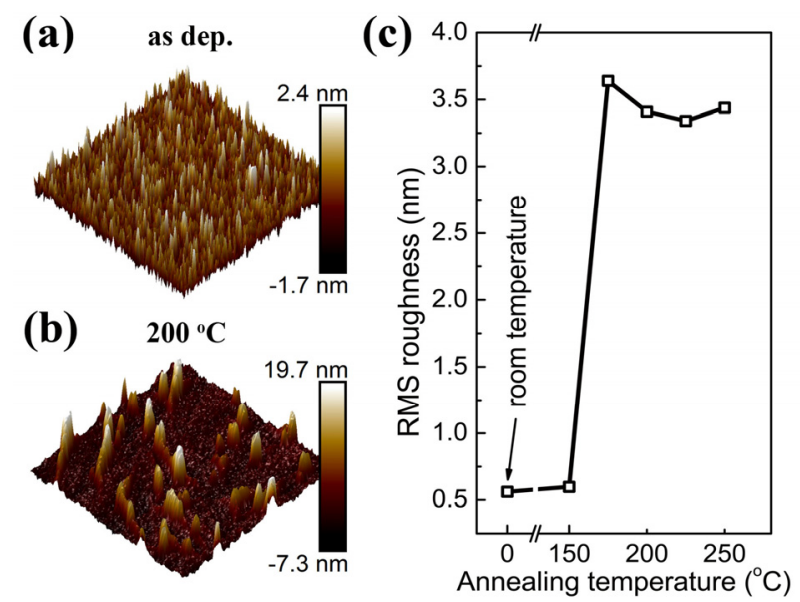

FIG. 4. AFM images of (a) as-deposited $\mathrm{SnO}_{\mathrm{x}}$ film and (b) film annealed at $200{ }^{\circ} \mathrm{C}$. The scanning size of the AFM images is $1 \mu \mathrm{m} \times 1 \mu \mathrm{m}$. (c) Root-mean-square (RMS) roughness of the films as a function of annealing temperature.

To study the nature of the clusters shown in Figs. 3 and 4, we note that previous studies showed that Sn atoms tend to precipitate to the dislocations and grain boundaries and then form Sn quantum dots in the Sn-rich $\mathrm{SiO}_{2}$ films during annealing. ${ }^{24}$ Lei et al. ${ }^{25}$ also reported a voidmediated formation of Sn quantum dots in a Si matrix. In their studies, voids below Si surface were induced by the lattice mismatch strain and Sn atoms were found to diffuse into these voids. The phenomenon in our experiment may be quite similar to these experiments. In our case, the microgrooves appeared when grain boundaries of polycrystalline $\mathrm{SnO}$ was formed when the films were annealed at $175^{\circ} \mathrm{C}$ as confirmed by XRD. ${ }^{26}$ As such, the microgrooves could well be the grain boundaries of polycrystalline $\mathrm{SnO}$. These microgrooves could act as defects that promote the crystal nucleation of metallic Sn, and the high diffusivity of Sn enabled the $\mathrm{Sn}$ crystals to grow along the sidewalls of the microgrooves in the annealed films. Furthermore, metallic Sn nucleated along the sidewalls of the microgrooves is expected to reduce the interfacial trap states at the grain boundaries of polycrystalline SnO. During annealing process at and above $162{ }^{\circ} \mathrm{C}$ (Figs. 3(d-f)), the original dispersed and continuously spread excess $\mathrm{Sn}$ in the as-deposited film quite possibly gathered to form Sn clusters along the microgrooves as in Refs. 24 and 25. The diameters of the clusters are $30 \pm 9 \mathrm{~nm}$ as estimated by SEM. Indeed, the XRD spectra reveal the formation of polycrystalline $\mathrm{Sn}$ at annealing temperatures at and above $175^{\circ} \mathrm{C}$. Also, the conductivity of the film dropped dramatically after the film was annealed in agreement with the formation of isolated (and hence not able to contribute to the film 
conductivity) Sn clusters. Obviously, the segregation of Sn clusters leads to a drastic reduction of $\mathrm{Sn}_{\mathrm{i}}$ in the $\mathrm{SnO}$ film. According to the first-principle calculations of native defects in $\mathrm{SnO}$, $\mathrm{Sn}_{\mathrm{i}}$ is found to induce a huge amount of defect states in the bandgap of $\mathrm{SnO} .{ }^{27}$ As such, the reduction of $\mathrm{Sn}_{\mathrm{i}}$ due to segregation of $\mathrm{Sn}$ at the sidewalls of the microgrooves makes it easier to shift the Fermi level. ${ }^{6,11}$ Because the bandgap of $\mathrm{SnO}$ is only $0.7 \mathrm{eV}$, the reduction of subgap states may well enable the ambipolar behavior. Indeed, the TFTs annealed at 175 and $200{ }^{\circ} \mathrm{C}$ exhibited improved $S S$, low $I_{\text {off, }}$ and ambipolar conduction. The TFT annealed at $225^{\circ} \mathrm{C}$ showed much larger $I_{\text {off }}$ and $D_{\mathrm{t}}$ than those annealed at $200{ }^{\circ} \mathrm{C}$, and the ambipolar behavior disappeared with the disappearance of n-type conduction. This may be due to the excess trap states caused by the formation of oxidized impurities such as $\mathrm{Sn}_{3} \mathrm{O}_{4}$ and $\mathrm{SnO}_{2}\left(\mathrm{Sn}_{3} \mathrm{O}_{4}\right.$ was detected by XRD when the TFT was annealed at $225^{\circ} \mathrm{C}$, and $\mathrm{Sn}_{3} \mathrm{O}_{4}$ can easily transform to $\mathrm{SnO}_{2}$.). These trap states, including both shallow and deep trap states, make it difficult to shift the Fermi level, and as a result, the ambipolar behavior disappeared. The shallow traps led to

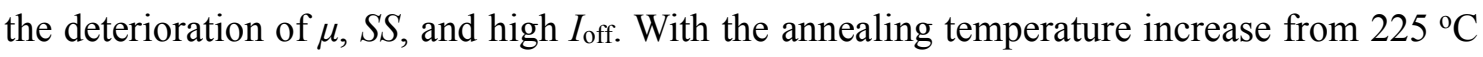
to $250^{\circ} \mathrm{C}$, both $I_{\mathrm{on}}$ and $I_{\text {off }}$ significantly decreased, and this should be due to the disproportionation reaction " $\mathrm{SnO} \rightarrow \mathrm{SnO}_{2}+\mathrm{Sn}$ " was activated at $250{ }^{\circ} \mathrm{C} .{ }^{23}$ Consequently, the obviously reduced amount of $\mathrm{SnO}$ led to the clear decrease of the hole concentration and drain current.

In conclusion, we have fabricated ambipolar $\mathrm{SnO}_{\mathrm{x}}$ TFTs by applying a high sputtering power of $200 \mathrm{~W}$ and post-annealing treatments. The ambipolar behavior was studied and discussed in the light of characterisation of the film morphology and composition. The results suggest that segregation of excess $\mathrm{Sn}$ on the sidewalls of the microgrooves leads to the reduction of density of subgap trap states by $\mathrm{Sn}$ interstitials in $\mathrm{SnO}$, making it possible to shift the Fermi level effectively by the gate voltage. As the ambipolar oxide TFT is highly attractive for CMOS-like applications, our results may have useful implications in achieving and optimizing ambipolar behavior in $\mathrm{SnO}_{\mathrm{x}}$ films for thin-film-based circuits. In addition, the optimum processing temperature for the ambipolar $\mathrm{SnO}_{\mathrm{x}} \mathrm{TFT}$ is below $200{ }^{\circ} \mathrm{C}$, so that the results are relevant to possible applications on flexible substrates such as polyimide.

This work was financed by the National Key Research and Development Program of China (Grant No. 2016YFA0301200 and 2016YFA0201800), the National Natural Science 
Foundation of China (Grant Nos. 11374185), Engineering and Physical Sciences Research Council (EPSRC) (Grant No. EP/N021258/1), China Postdoctoral Science Foundation funded project (2016M590634), the Key Research and Development Program of Shandong Province (2017GGX10111 and 2017GGX10121), the Natural Science Foundation of Jiangsu Province (BK20151255), Suzhou Planning Projects of Science and Technology (SYG201527 and SYG201616), and the Fundamental Research Fund of Shandong University (2016WLJH44).

${ }^{1}$ Kim Kyung Min, Kim Chi Wan, Heo Jae-Seok, Na Hyungil, Lee Jung Eun, Park Chang Bum, Bae Jong-Uk, Kim Chang-Dong, Jun Myungchul, Hwang Yong Kee, S. T. Meyers, A. Grenville, and D. A. Keszler, Appl. Phys. Lett. 99 (24), 242109 (2011).

${ }^{2}$ Binn Kim, Hyung Nyuck Cho, Woo Seok Choi, Seung-Hee Kuk, Yong Ho Jang, Juhn-Suk Yoo, Soo Young Yoon, Myungchul Jun, Yong-Kee Hwang, and Min-Koo Han, IEEE Electron Device Lett. 33 (4), 528 (2012).

${ }^{3}$ E. Fortunato, P. Barquinha, and R. Martins, Adv. Mater. 24 (22), 2945 (2012).

${ }^{4}$ J. Zhang, Y. Li, B. Zhang, H. Wang, Q. Xin, and A. Song, Nat. Commun. 6, 7561 (2015).

${ }^{5}$ L. Y. Liang, H. T. Cao, X. B. Chen, Z. M. Liu, F. Zhuge, H. Luo, J. Li, Y. C. Lu, and W. Lu, Appl. Phys. Lett. 100 (26), 263502 (2012).

${ }^{6}$ H. Luo, L. Liang, H. Cao, M. Dai, Y. Lu, and M. Wang, ACS Appl. Mater. Interfaces 7 (31), 17023 (2015).

${ }^{7}$ H. Luo, L. Y. Liang, Q. Liu, and H. T. Cao, ECS J. Solid State Sci. Technol. 3 (9), Q3091 (2014).

${ }^{8}$ E. J. Meijer, D. M. de Leeuw, S. Setayesh, E. van Veenendaal, B. H. Huisman, P. W. Blom, J. C. Hummelen, U. Scherf, J. Kadam, and T. M. Klapwijk, Nat. Mater. 2 (10), 678 (2003).

${ }^{9}$ S. Z. Bisri, C. Piliego, J. Gao, and M. A. Loi, Adv. Mater. 26 (8), 1176 (2014).

${ }^{10}$ Anand Subramaniam, Kurtis D. Cantley, Harvey J. Stiegler, Richard A. Chapman, and Eric M. Vogel, IEEE Trans. Electron Devices 59 (2), 359 (2012).

${ }^{11}$ K. Nomura, T. Kamiya, and H. Hosono, Adv. Mater. 23 (30), 3431 (2011).

${ }^{12}$ Z. Wang, P. K. Nayak, J. A. Caraveo-Frescas, and H. N. Alshareef, Adv. Mater. 28 (20), 3831 (2016).

${ }^{13}$ Toshio Kamiya, Kenji Nomura, and Hideo Hosono, Sci. Technol. Adv. Mater. 11 (4), 044305 (2010).

${ }^{14}$ Yoichi Ogo, Hidenori Hiramatsu, Kenji Nomura, Hiroshi Yanagi, Toshio Kamiya, Mutsumi Kimura, Masahiro Hirano, and Hideo Hosono, Phys. Status Solidi A 206 (9), 2187 (2009).

${ }^{15}$ Jeong Chan-Yong, Lee Daeun, Han Young-Joon, Choi Yong-Jin, and Kwon Hyuck-In, Semicond. Sci. Tech. 30 (8), 085004 (2015).

${ }^{16}$ J. A. Caraveo-Frescas and H. N. Alshareef, Appl. Phys. Lett. 103 (22), 222103 (2013).

${ }^{17}$ Haowei Peng, Andre Bikowski, Andriy Zakutayev, and Stephan Lany, APL Mater. 4 (10), 106103 (2016).

${ }^{18}$ Jiawei Zhang, Xi Kong, Jia Yang, Yunpeng Li, Joshua Wilson, Jie Liu, Qian Xin, Qingpu Wang, and Aimin Song, Appl. Phys. Lett. 108 (26), 263503 (2016).

${ }^{19}$ Po-Chun Chen, Yung-Hsien Wu, Zhi-Wei Zheng, Yu-Chien Chiu, Chun-Hu Cheng, Shiang-Shiou Yen, HsiaoHsuan Hsu, and Chun-Yen Chang, J. Disp. Technol. 12 (3), 224 (2016).

${ }^{20}$ Soo Hyun Kim, In-Hwan Baek, Da Hye Kim, Jung Joon Pyeon, Taek-Mo Chung, Seung-Hyub Baek, Jin-Sang Kim, Jeong Hwan Han, and Seong Keun Kim, J. Mater. Chem. C 5 (12), 3139 (2017).

${ }^{21}$ F. Lawson, Nature 215 (5104), 955 (1967).

${ }^{22}$ R. Zenkyu, D. Tajima, and J. Yuhara, J. Appl. Phys. 111 (6), 064907 (2012).

${ }^{23}$ Hao Luo, Ling Yan Liang, Hong Tao Cao, Zhi Min Liu, and Fei Zhuge, ACS Appl. Mater. Interfaces 4 (10), 5673 (2012). 
${ }^{24}$ S. Huang, E. C. Cho, G. Conibeer, M. A. Green, D. Bellet, E. Bellet-Amalric, and S. Y. Cheng, J. Appl. Phys. 102 (11), 6 (2007).

${ }^{25}$ Y. Lei, P. Mock, T. Topuria, N. D. Browning, R. Ragan, K. S. Min, and H. A. Atwater, Appl. Phys. Lett. 82 (24), 4262 (2003).

${ }^{26}$ Y. H. Jiang, I. C. Chiu, P. K. Kao, J. C. He, Y. H. Wu, Y. J. Yang, C. C. Hsu, I. C. Cheng, and J. Z. Chen, Appl. Surf. Sci. 327358 (2015).

${ }^{27}$ A. Togo, F. Oba, I. Tanaka, and K. Tatsumi, Phys. Rev. B 74 (19), 195128 (2006). 